\title{
Application of Response Surface Methodology for Optimization of Urea Grafted Multiwalled Carbon Nanotubes in Enhancing Nitrogen Use Efficiency and Nitrogen Uptake by Paddy Plants
}

\author{
Norazlina Mohamad Yatim, ${ }^{1}$ Azizah Shaaban, ${ }^{1}$ Mohd Fairuz Dimin, ${ }^{1}$ \\ Faridah Yusof, ${ }^{2}$ and Jeefferie Abd Razak ${ }^{3}$ \\ ${ }^{1}$ Engineering Materials Department, Faculty of Manufacturing Engineering, Universiti Teknikal Malaysia Melaka, \\ Hang Tuah Jaya, 76100 Durian Tunggal, Melaka, Malaysia \\ ${ }^{2}$ Department of Biotechnology Engineering, Kulliyyah of Engineering, International Islamic University Malaysia, \\ P.O. Box 10, 50728 Kuala Lumpur, Malaysia \\ ${ }^{3}$ Carbon Research Technology Research Group, Engineering Materials Department, Faculty of Manufacturing Engineering, \\ Universiti Teknikal Malaysia Melaka, Hang Tuah Jaya, 76100 Durian Tunggal, Melaka, Malaysia \\ Correspondence should be addressed to Norazlina Mohamad Yatim; ly2110@hotmail.com
}

Received 6 June 2016; Accepted 20 July 2016

Academic Editor: Valery Khabashesku

Copyright (C) 2016 Norazlina Mohamad Yatim et al. This is an open access article distributed under the Creative Commons Attribution License, which permits unrestricted use, distribution, and reproduction in any medium, provided the original work is properly cited.

\begin{abstract}
Efficient use of urea fertilizer (UF) as important nitrogen (N) source in the world's rice production has been a concern. Carbonbased materials developed to improve UF performance still represent a great challenge to be formulated for plant nutrition. Advanced $\mathrm{N}$ nanocarrier is developed based on functionalized multiwall carbon nanotubes (f-MWCNTs) grafted with UF to produce urea-multiwall carbon nanotubes (UF-MWCNTs) for enhancing the nitrogen uptake (NU) and use efficiency (NUE). The grafted $\mathrm{N}$ can be absorbed and utilized by rice efficiently to overcome the $\mathrm{N}$ loss from soil-plant systems. The individual and interaction effect between the specified factors of f-MWCNTs amount (0.10-0.60 wt\%) and functionalization reflux time (12-24 hrs) with the corresponding responses (NUE, NU) were structured via the Response Surface Methodology (RSM) based on five-level CCD. The UF-MWCNTs with optimized $0.5 \mathrm{wt} \% \mathrm{f}-\mathrm{MWCNT}$ treated at $21 \mathrm{hrs}$ reflux time achieve tremendous NUE up to $96 \%$ and NU at $1180 \mathrm{mg} /$ pot. Significant model terms ( $p$ value $<0.05$ ) for NUE and NU responses were confirmed by the ANOVA. Homogeneous dispersion of UF-MWCNTs was observed via FESEM and TEM. The chemical changes were monitored by FT-IR and Raman spectroscopy. Hence, this UF-MWCNTs' approach provides a promising strategy in enhancing plant nutrition for rice.
\end{abstract}

\section{Introduction}

Nitrogen $(\mathrm{N})$ had a critical role in paddy growth and productivity, as it is required for the synthesis of many essential molecules including nucleic acids (DNA and RNA), amino acids, and proteins [1-3]. Referring to the International Fertilizer Association (IFA) in the Fertilizer Outlook for the years of 2013-2017, the global N demand was projected to grow into 107.5 million metric tons of $\mathrm{N}$. This scenario shows the larger demand for $\mathrm{N}$ by the agricultural sector. Even though $\mathrm{N}$ based fertilizers were supplied directly to the crops in the form of liquid and pelletized, however increasing the NUE and NU was tremendously difficult as plants normally take up $\mathrm{N}$ in the form of nitrate or ammonium ions [4]. It was reported that between 50 and $70 \%$ of the nitrogenous fertilizer is lost through leaching and gas emission of ammonia and nitrogen oxides to the atmosphere [5]. These may contribute to unfavourable environmental impact and higher operational cost to farmers. Uncontrolled applications of UF create an adverse effect on aquatic life due to eutrophication which had caused an excessive algae growth. Therefore, high NUE and NU of fertilizer $\mathrm{N}$ are important characteristics to ensure enough and lower cost $\mathrm{N}$ source for efficient paddy growth. 
Recent development in carbon nanomaterials including MWCNTs as smart delivery system for efficient plant growth was widely explored due to their interface with plant organelles imparting new and enhanced function of this part. Earlier, research on smart delivery systems in agriculture was reported on the delivery of pesticides encapsulated in carbon NMs for UV-shielding [6] and assisted delivery of genetic material for crop improvement [7]. The potential applications of nanomaterials in the agricultural sector have been highlighted in the previous research conducted by Ghormade et al. [8] and Wilson et al. [9]. Nanomaterials had potential applications in assisting the control and slow release of fertilizer due to their unique properties of specific targets with multifunctional characteristics avoiding biological barriers for a high effect [10]. In fact, nanomaterials had been proven to be able to increase the agriculture yield by optimizing the nutrient management of the plants [11-16]. Nanomaterials delivery system is targeting the plant to take up nutrients efficiently and enhance the germination rate of plants by improving the intake of water as well as oxygen $[17,18]$. Hence, leaching and losses of nutrients to unintended targets like soil are reduced.

Owing to their special physicochemical properties, MWCNTs having transport properties [19] and unique ability as molecular delivery through plant cells wall [20], which stimulates crop growth, improve the soil environment and promote crop growth metabolism [21-23]. These scenarios made MWCNTs very promising for recent progress in the agricultural research activities and utilization. Research on the impact of carbon-based nanomaterials combined with fertilizer on plants was reported by Liu et al. [24]. They had found that the presence of nanomaterials has increased the yield and quality of winter wheat crop, indicating a significant saving effect on the utilization of nitrogenous type fertilizer. A study of the effects of carbon nanomaterials fertilizer on late rice by Yin-fei et al. [25] in the double rice season area at the south of China revealed that the use of carbon NMs fertilizer would increase the number of glume flowers per year, fertility, and the rice yield. Concurrently, the carbon nanomaterials fertilizer was observed to slow down the fertilizer release rate, hence reducing the amount of fertilizer utilization improving the NUE. These positive results agreed well with the role of carbon nanomaterials in fertilizer application for the enhancement of plant growth and yield. Hence, this encouraged further research to be undertaken in exploring the potential of nanomaterials to be integrated or embedded with fertilizer for the sake of agricultural field. This effort had improved the efficacy of nitrogenous based fertilizer especially in urea for paddy growth purposes.

In this study, development of such enhanced UF combined with f-MWCNTs was systematically structured by the statistical design for an optimum operational condition determination. The empirical statistical technique utilizing the Response Surface Methodology (RSM) was applied to determine the regression model and optimum operating condition as well as the interaction effects of design factors onto the desired responses studied [26-28]. This analysis approach is suitable for a multifactor experiment in determining the correlation effects between the factors of the most optimum processing condition. The objective of this work is to determine the effects of several design factors like f-MWCNTs wt $\%$ and functionalization reflux time on the performance of UF-MWCNTs in terms of their NUE, NU, and Total Dry Weight (TDW) using the CCD approach via RSM analysis by Design Expert 9.0, Stat Ease, USA.

\section{Materials and Methods}

2.1. Materials. Chemical vapour deposition grown MWCNTs were purchased from a commercial source (stock: 214 Cahaya Tech (M) Private Ltd.). The MWCNTs were characterized by the company as follows: purity of $95 \%$, outside diameter of $10-20 \mathrm{~nm}$, inside diameter of $5-10 \mathrm{~nm}$, and length ranging from $0.5 \mu \mathrm{m}$ to $1.0 \mu \mathrm{m}$. Analytical chemical grade (Merck) of nitric acid $\left(\mathrm{HNO}_{3}\right)(69 \%)$ was used as received. Rice plants (code MR219) were collected from farmers at Tanah Merah, Kelantan, Malaysia. MR219 paddy variety was selected in this work, considering the variety's common availability in the Malaysian local market and easy-growing nature. MR219 was derived between the MR137 and MR151 with maturation period of 105-111 days after sowing. This variety was released for the commercialization by the Malaysian Agricultural Research and Development Institute (MARDI) on the year of 2001 [29].

2.2. Preparation of UF-MWCNTs Fertilizer. Typically, $1.50 \mathrm{mg}$ of as-received MWCNTs was added to a 500-mL round bottom flask containing $450 \mathrm{~mL}$ of nitric acid for functionalization process. After being refluxed at $100^{\circ} \mathrm{C}$ for $12,15,18$, 21 , and $24 \mathrm{~h}$, the suspension was naturally cooled down to room temperature. The black solution known as f-MWCNTs was vacuum-filtered using a $3 \mu \mathrm{m}$ particle retention filter paper and washed with deionized water to remove excess $\mathrm{HNO}_{3}$ until it became neutral. The f-MWCNTs were dried in a vacuum oven at $105^{\circ} \mathrm{C}$ for at least $2 \mathrm{hrs}$. Various amounts (0.1-0.6 wt $\%)$ of $\mathrm{f}-\mathrm{MWCNTs}$ were sonicated and then stirred together with urea for $6 \mathrm{hrs}$ at $150 \mathrm{rpm}$ to produce UFMWCNTs. The samples were dried in oven at $70^{\circ} \mathrm{C}$ for at least 5 hours.

2.3. Plant Materials and Growth Conditions. The MR219 rice seeds were rinsed, thoroughly soaked for $24 \mathrm{hrs}$ in water, and germinated in plastic containers. Seedlings were transferred into pots containing rice field soil of $0.2 \% \mathrm{~N}$-content. After sowing, the UF-MWCNTs fertilizer was applied three times (at 14,35 , and 55 days) with a rate of $120 \mathrm{~kg} \mathrm{ha}^{-1}$. Ordinary fertilizers such as phosphorus (DAP) and potassium (muriate of potash) were applied once at a rate of $50 \mathrm{kgha}^{-1}$.

\subsection{Optimization by Response Surface Methodology (RSM).} In order to determine the optimum level of design parameters for UF-MWCNTs fertilizer production, Central Composite Design (CCD) of RSM was applied. The selected design parameters used are in accordance with the previous work reported by [30]. The weight $\%$ of f-MWCNTs and functionalization reflux time were assessed at five levels: -1.682 , $-1,0,+1$, and +1.682 as presented in Table 1 . A total of 13 experiments (refer to Table 2) were conducted for the 
TABLE 1: Experimental codes and levels of independent variables for RSM optimization.

\begin{tabular}{|c|c|c|c|c|c|c|}
\hline \multirow{2}{*}{ Variables } & \multirow{2}{*}{ Units } & \multicolumn{5}{|c|}{ Levels } \\
\hline & & -1.682 & -1 & 0 & +1 & +1.682 \\
\hline MWCNTs, $X_{1}$ & wt $\%$ & 0.1 & 0.2 & 0.3 & 0.5 & 0.6 \\
\hline $\begin{array}{l}\text { Functionalization } \\
\text { reflux time, } X_{2}\end{array}$ & Hour & 12 & 15 & 18 & 21 & 24 \\
\hline
\end{tabular}

TABLE 2: Experimental design matrix.

\begin{tabular}{lcc}
\hline Run & $\begin{array}{c}\text { Factor 1 } \\
\text { MWCNTs (wt\%) }\end{array}$ & $\begin{array}{c}\text { Factor 2 } \\
\text { Functionalization } \\
\text { reflux time (hour) }\end{array}$ \\
\hline 1 & 0.6 & 18.00 \\
2 & 0.3 & 18.00 \\
3 & 0.3 & 24.00 \\
4 & 0.3 & 18.00 \\
5 & 0.3 & 18.00 \\
6 & 0.3 & 12.00 \\
7 & 0.5 & 21.00 \\
8 & 0.1 & 15.00 \\
9 & 0.2 & 18.00 \\
10 & 0.1 & 21.00 \\
11 & 0.3 & 18.00 \\
12 & 0.5 & 15.00 \\
13 & 0.3 & 18.00 \\
\hline
\end{tabular}

optimization of two chosen design factors. The responses were NUE, NU, and TDW with three replications for every set of trials.

2.5. Statistical Analysis and Modelling. The experimental results were fitted into the second-order polynomial regression equation (refer to (1)) and the analysis of variance (ANOVA) was conducted:

$$
Y=\beta_{\circ}+\sum_{i} \beta_{i} X_{i}+\sum_{i i} \beta_{i i} X_{i i}^{2}+\sum_{i j} \beta_{i j} X_{i} X_{j}
$$

in which $Y_{i}$ is the predicted response, $X_{i}$ and $X_{j}$ are independent variables, $\beta_{\circ}$ is the offset term, $\beta_{i}$ is the $i$ th linear coefficient, $\beta_{i i}$ is the $i$ th quadratic coefficient, and $\beta_{i j}$ is the $i j$ th interaction coefficient [31].

The statistical software package, Design Expert 9 (Stat Ease, Inc., Minneapolis, MN, USA), was used for the regression analysis of the experimental data and also to plot the response surface graphs. The multiple coefficients of correlation $R$ and the determination coefficient of correlation $R^{2}$ were calculated to evaluate the performance of the regression equation [32]. The fitted polynomial equation was then expressed in the form of three-dimensional (3D) surface plots, in order to illustrate the relationship between the responses and the experimental levels of each design factors tested in this study. The point optimization method was employed in order to optimize the level of each variable for maximum response. The optimum levels of the selected variables were obtained by analyzing the response surface plots [33].

\subsection{Morphological Observation Using Transmission Electron Microscopy (TEM) and Field Emission Scanning Electron} Microscope (FESEM). Samples were cut with Leica Ultracut UCT ultramicrotome into ultrathin sections of approximately $80 \mathrm{~nm}$ thick and then cooled using liquid $\mathrm{N}$ before being placed onto copper grid. Next, morphological studies were conducted by using Hitachi HT-7700 Transmission Electron Microscopy (TEM). Further Field Emission Scanning Electron Microscope (FESEM) was performed using model Hitachi SU8000 where point and mapping for elemental composition were also carried out using Energy Dispersive X-Ray (EDX) Analysis.

2.7. Chemical Characterization. Fourier transformed-IR (FTIR) spectra were used to confirm the functional groups of $\mathrm{f}$ MWCNTs and UF-MWCNTs fertilizer, obtained on a Jasco FTIR-6100 with attenuated total reflectance (ATR) method. Each sample was scanned with resolution $4 \mathrm{~cm}^{-1}$ within the range $400-4000 \mathrm{~cm}^{-1}$ to obtain the spectrum. Raman spectroscopy was carried out with excitation laser source 532 nm, UniRAM-3500, micro Raman Mapping chamber.

2.8. Plant Yield Analysis. Harvested plants were dried in an oven at $100^{\circ} \mathrm{C}$ for 24 hours, and individual weights were recorded as Total Dry Weight (TDW). Consequently, they were ground for total N-content analysis. According to the Kjeldahl method [6], the content of $\mathrm{N}\left(w_{\mathrm{N}}\right)$, in milligrams per gram, is calculated using the following formula:

$$
w_{\mathrm{N}}=\frac{\left(v_{1}-v_{0}\right) c\left(H^{+}\right) M_{\mathrm{N}} 100}{\left(m \times m_{t}\right)}
$$

where $v_{1}$ is the volume, in $\mathrm{mL}$, of the sulfuric acid used in the titration of the sample, $v_{0}$ is the volume, in millilitres, of the sulfuric acid used in the titration of the blank test, $c\left(H^{+}\right)$is the concentration of $\mathrm{H}^{+}$in the sulfuric acid in moles per litre (e.g., if $0.01 \mathrm{~mol} / \mathrm{L}$ sulfuric acid is used, $c\left(H^{+}\right)=0.02 \mathrm{~mol} / \mathrm{L}$ ), $M_{\mathrm{N}}$ is the molar mass of $\mathrm{N}$, in grams per mole (14), $m$ is the mass of test sample, and $m_{t}$ is the dry residue, expressed as $\mathrm{g} / 100 \mathrm{~g}$ on the basis of oven dried material according to the standard of the spatial material.

Furthermore, NUE analysis was carried out in isotopicaided fertilizer experiments, where UF-MWCNTs fertilizer labelled with ${ }^{15} \mathrm{~N}$ urea isotope (5\% atom, Isotec) is used and the amount of $\mathrm{N}$ fertilizer that a plant has taken up is determined. The plant samples for ${ }^{15} \mathrm{~N}$ were analyzed by using emission spectrometer detector $\left(\mathrm{NO}_{17}\right)$, FAN (Fischer Analysen Instrumente), Germany. In this way $\mathrm{N}$ fertilizer uptake and use by paddy can be studied. Basically, $2 \%$ atom ${ }^{15} \mathrm{~N}$ urea was enough to be detected by the emission spectrometer. Fertilizer $\mathrm{N}$ utilization by crops and retention in the soil were 
calculated using ${ }^{15} \mathrm{~N}$ direct technique calculation as showed in [34]

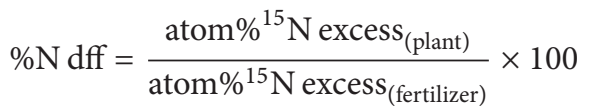

$$
\begin{aligned}
& \mathrm{N} \text { uptake by plant }=\text { Dry weight } \text { plant } \times \frac{\% \mathrm{~N}}{100}
\end{aligned}
$$

$$
=\mathrm{N} \text { uptake by plant } \times \frac{\% \mathrm{~N} \mathrm{dff} \text { plant }}{100}
$$

Fertilizer $\mathrm{N}$ utilization by plant

$$
=\frac{\text { Fertilizer } \mathrm{N} \text { uptake by plant }}{\mathrm{N} \text { applied }} \times 100,
$$

where $\mathrm{N}$ dff is fraction of $\mathrm{N}$ in the plant derived from the ${ }^{15} \mathrm{~N}$ labelled fertilizer.

\section{Results and Discussion}

3.1. The Morphological Observation of $f-M W C N T s$ and UFMWCNTs Using Transmission Electron Microscopy (TEM). The morphologies of $\mathrm{f}-\mathrm{MWCNT}$ and urea-MWCNTs (UFMWCNTs) were shown in Figures 1(a)-1(f). Prior to strong acid treatment, the f-MWCNTs exhibit the presence of many opened ends' tube without significantly altering their sidewalls structure. Figure 1(a) had revealed that the morphology of f-MWCNTs up to $21 \mathrm{hrs}$ oxidation period still retained their hollow nanotubes structure with proper alignment of multiwalls. Besides, the f-MWCNTs having relatively high concentration of $\mathrm{COOH}$ groups on the MWCNTs, which have been confirmed through FT-IR evaluation later, appeared to possess long tubes and separated into individual nanotubes. By careful examination, the nitric acid treatment limits functionalization process mostly to the opening of tube caps and formation of functional groups at the defect sites along the sidewalls as can be seen in Figures 1(b) and 1(c). However, it was also reported that the carboxylic functional groups that were detected at the open end and at the sidewall of MWCNTs were introducing the damage on the tube walls and shorten the tubes length [35]. Yet, as revealed in Figures 1(b) and 1(c), under less vigorous conditions of refluxing in nitric acid, shortening of the tubes might be minimized. Additionally, the presence of carboxyl groups and attachment of UF on f-MWCNTs lead to a reduction of van der Waals interactions among the tubes, which strongly facilitates the separation of nanotube bundles into individual tubes as can be seen clearly in Figures 1(a) and 1(d).

Furthermore, the two-step functionalization of nanotubes through the oxidative introduction of carboxyl groups followed by the formation of amide or ester linkages through the interaction with UF does allow for a significant effect on the restructuring aligned MWCNTs. By comparison, Figure 1(d) showed clearly rougher and nonaligned sidewalls with shorter MWCNTs after being grafted with UF. There are also more opened end tubes observed. Additionally, grafting the amide groups on the carboxyl groups at the f-MWCNTs surfaces does not change the hollow nanotubes structure.

By examining carefully f-MWCNTs (Figures $1(\mathrm{a})-1(\mathrm{c})$ ) and UF-MWCNTs (Figures 1(d)-1(f)), there were differences in their open end tubes. Figures 1(e) and 1(f) reveal that the openings of f-MWCNTs after grafting with UF were not in uniform cutting and broader in area. This might be strongly the effect of grafting process which occured at the open end nanotubes where most carboxyl groups were available after nitric acid treatment. Though the size of inside and outside diameter of nanotubes does not show significant changes, the hollow structure of f-MWCNTs grafted with UF seems to be narrower due to unaligned sidewalls. These results could indicate that even grafting process as reaction of f-MWCNTs with UF further opening more nanotubes ends, modifying their sidewalls, and cutting the MWCNTs into shorter nanotubes, still retains their nanotubes structure to be explored as unique mobile properties for efficient $\mathrm{N}$ delivery.

3.2. Dispersion Observation of UF-MWCNTs Using Field Emission Scanning Electron Microscope (FESEM). Figure 2 illustrates FESEM micrographs of UF-MWCNTs fertilizer. Generally, as shown clearly in Figure 2(a), the morphology of UF shows much bigger particle range from 10 to $100 \mu \mathrm{m}$ compared to f-MWCNTs $(10-20 \mathrm{~nm})$. Using higher magnification, their dispersion behaviour was illustrated in Figures 2(b) and 2(c). f-MWCNTs were found dispersed homogeneously on the surface of urea particles. This excellent biocompatibility is conveyed by hydrophilic properties possessed by f-MWCNTs affording a stable dispersion [36] in UF. This makes the UF surfaces become rougher and abundant with f-MWCNTs attached. However, addition of fMWCNTs in a small quantity $(0.1-0.6 \mathrm{wt} \%)$ results in their homogeneous dispersion performance shown only at certain urea particles. The f-MWCNTs are able to penetrate into the bigger particles of UF and chemically interact with them. Positively, this observation will be managed to expose the properties of UF-MWCNTs for agriculture application effectively.

Additionally, using much higher magnification of FESEM, the individual tubular structures of f-MWCNTs were observed clearly in Figure 2(d) instead of being agglomerated among each other. These findings were important to promote the ability of f-MWCNTs to be N molecular carrier in UFMWCNTs fertilizer into the plant cell wall. This is in agreement with Liu et al. [20] that reported that nonbundled fMWCNTs can penetrate plant cell wall with no apparent cell death observed. Also, aggregates MWCNTs that will retain exist in the soil and reveal toxicity properties were reported elsewhere [37-39]. They will clump together and cause cells apoptosis and increase of response oxidative stress (ROS) and when reaching living cells resulted in cell viability reduction and cell death even in low concentration [40]. Hence, this morphological observation is important to ensure that the f-MWCNTs are separated into individual tubes when interacting with UF. Furthermore, their ability to be mobile freely and carry $\mathrm{N}$ efficiently for plant nutrition can be utilized significantly. 


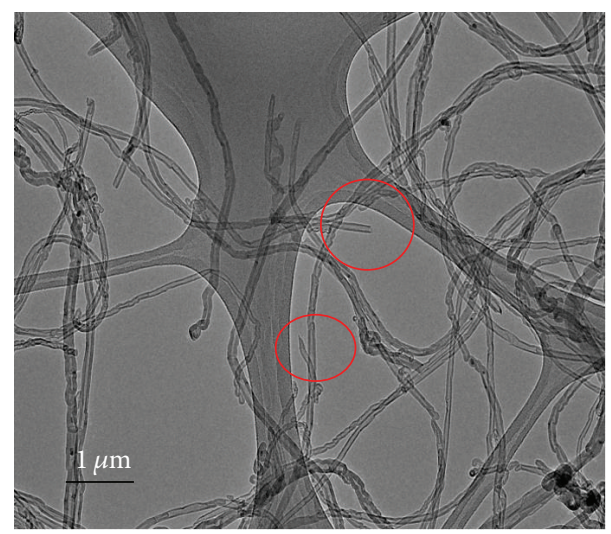

(a)

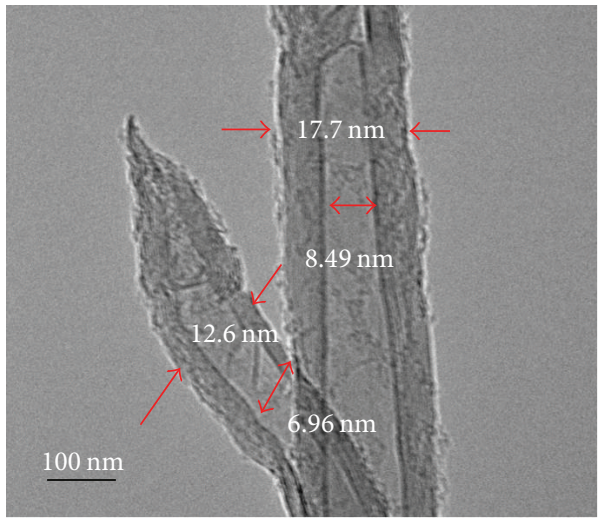

(c)

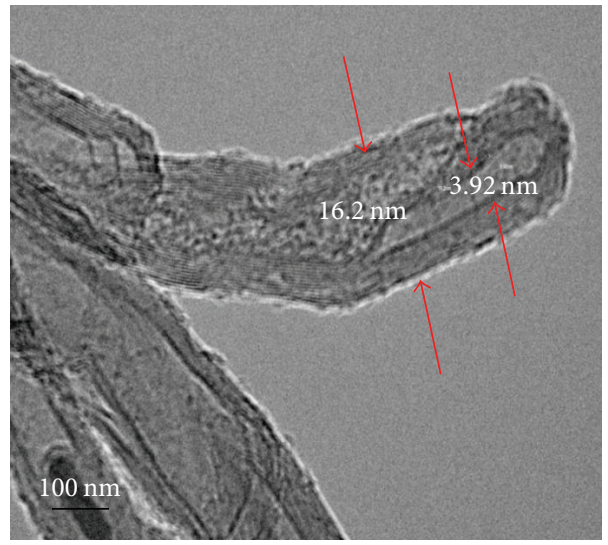

(e)

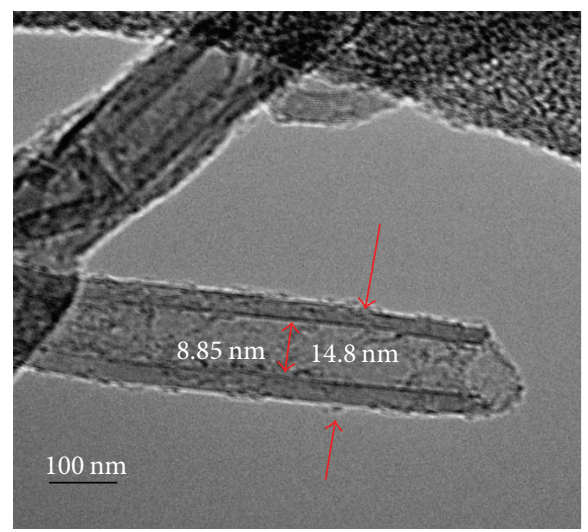

(b)

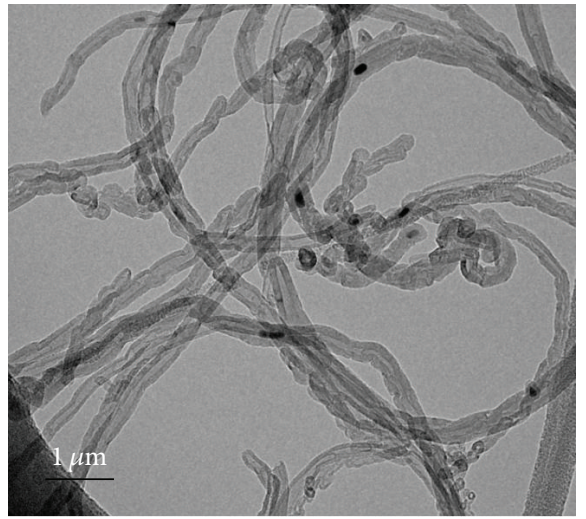

(d)

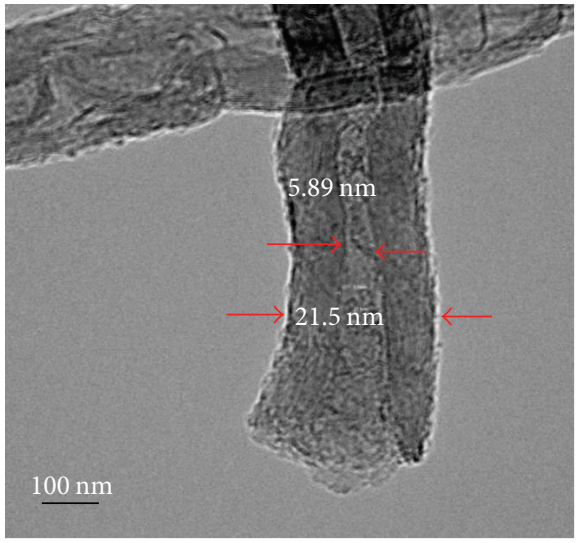

(f)

FIGURE 1: TEM micrographs of $(a-c)$ functionalized multiwall carbon nanotubes and $(d-f)$ urea grafted multiwall carbon nanotubes.

3.3. Surface Functional Group Determination by Fourier Transformed Infrared Spectroscopy (FT-IR). FT-IR aims to study any spectral changes in position or shape that occurred after grafting f-MWCNTs with UF. Through careful examination on the FT-IR spectra of f-MWCNTs and UF-MWCNTs illustrated in Figure 3, it is strongly suggested that covalent bonds occurred between $\mathrm{NH}_{2}$ groups of UF and carboxyl groups of f-MWCNTs upon reactions between urea and $\mathrm{f}-$ MWCNTs. The spectra of f-MWCNTs mainly characterized by bands at $3300-2500$ (O-H stretching vibration), $1700-$ $1725 \mathrm{~cm}^{-1}$ ( $\mathrm{C}=\mathrm{O}$ stretching vibration), and $1210-1320 \mathrm{~cm}^{-1}$ (C-O stretching vibration) correspond to the vibration of the carboxylic acid groups [41]. In the IR spectra of UF-MWCNTs, the bands around $1640-1690 \mathrm{~cm}^{-1}, 1510-$ $1600 \mathrm{~cm}^{-1}, 1376-1388 \mathrm{~cm}^{-1}$, and $1120-1290 \mathrm{~cm}^{-1}$ could be assigned to $\mathrm{C}=\mathrm{O}$ stretching vibration, $\mathrm{N}-\mathrm{H}$ bending, $\mathrm{CH}_{2}$ bending, and $\mathrm{C}-\mathrm{N}$ stretching. These spectral characteristics are attributed to amide [41]. 


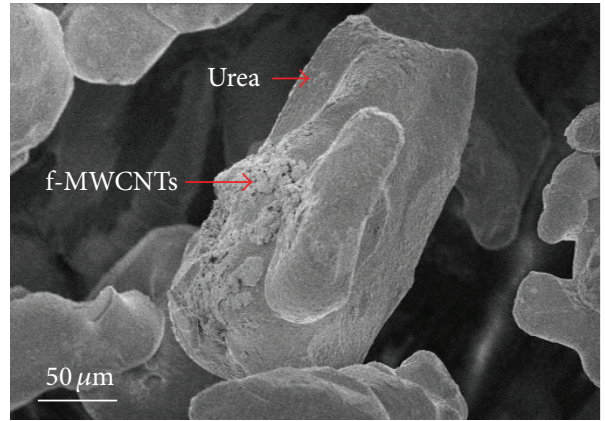

(a)

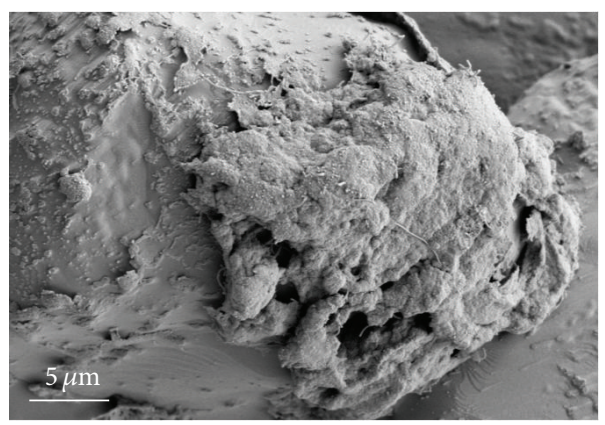

(c)

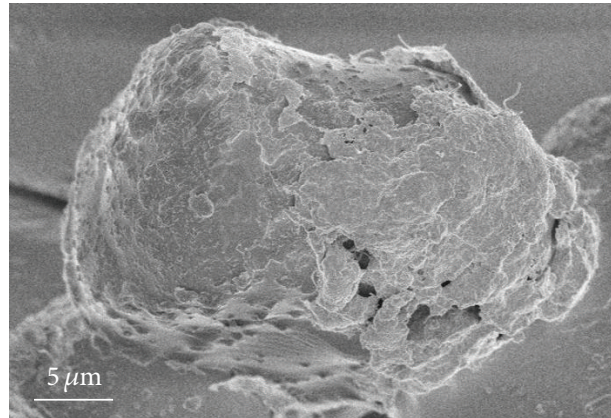

(b)

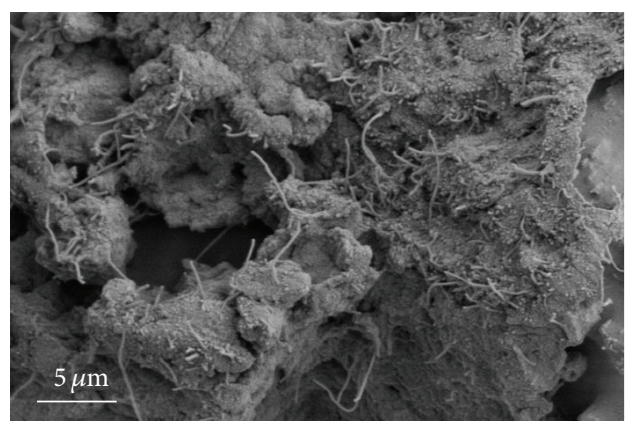

(d)

FiguRE 2: FESEM micrographs of UF-MWCNTs fertilizer.

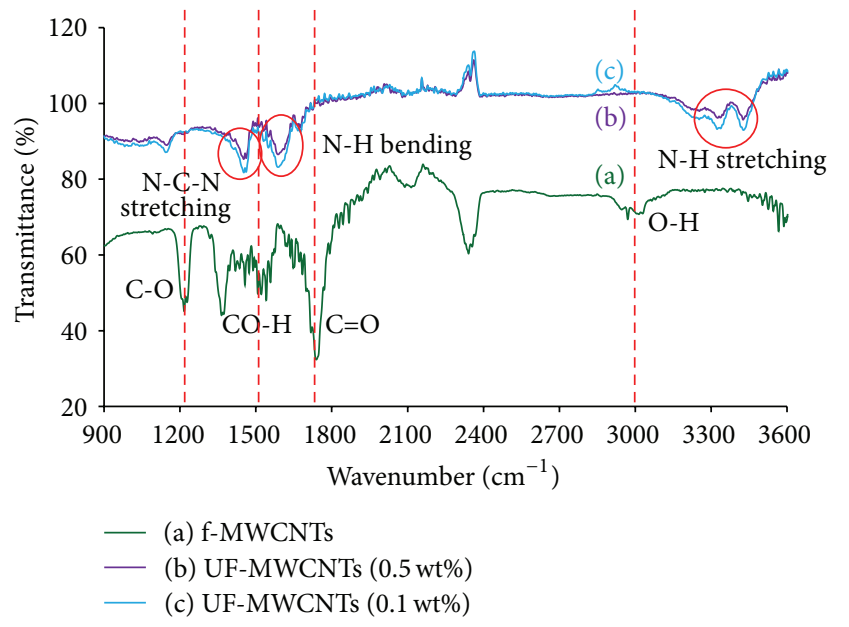

FIGURE 3: FT-IR spectra of (a) f-MWCNTs and UF-MWCNTs with (b) $0.5 \mathrm{wt} \% \mathrm{f}-\mathrm{MWCNTs}$ and (c) $0.1 \mathrm{wt} \% \mathrm{f}-\mathrm{MWCNTs}$.

Basically, the chemically inactive outer walls of MWCNTs will be activated through functionalization process on their sidewalls. Chemical functionalization is based on the production of covalent bond between the functional groups with the carbon of MWCNTs [42]. It can be performed at the end caps of nanotubes or at their sidewalls which may have many defects.

Any changes in peak position or shape reveal a change has happened in the distribution of frequencies included in that particular vibration mode. By comparing the FTIR spectra of f-MWCNTs with UF-MWCNTs, it could be seen that the transmission peak of $\mathrm{O}-\mathrm{H}$ stretching vibration at 3018 in the IR spectrum of f-MWCNTs disappeared in the IR spectrum of both UF-MWCNTs at different amount, strongly indicating that the $\mathrm{O}-\mathrm{H}$ groups in $\mathrm{f}-\mathrm{MWCNT}$ might be replaced with the amino groups in the UF during the functionalization process. Also, $\mathrm{C}=\mathrm{O}\left(1739 \mathrm{~cm}^{-1}\right)$ and $\mathrm{C}$ $\mathrm{O}\left(1219 \mathrm{~cm}^{-1}\right)$ stretching vibration attributed to $\mathrm{f}$-MWCNTs were observed to be replaced with new shape of transmission peak that appears, corresponding to $\mathrm{N}-\mathrm{H}$ bending and $\mathrm{C}-\mathrm{N}$ stretching vibration at 1519 and $1219 \mathrm{~cm}^{-1}$, respectively, after grafting process with UF. Similar observation was reported by Gao et al. [43] that claimed that $\mathrm{NH}_{2}$ groups from UF can react with the carboxyl groups $(\mathrm{COOH})$ on the surface of $\mathrm{f}$ MWCNTs and produce amide groups. Thus, the results from the FT-IR spectra confirm that chemical functionalization has occurred between f-MWCNTs and UF instead of physical functionalization (noncovalent) only.

3.4. Raman Spectroscopy Analysis. Raman spectroscopy analysis is highly sensitive to the morphology structures of graphitic materials such as MWCNTs and aims to determine particular spectral changes induced by covalent functionalization. Figure 4 depicts Raman analysis of f-MWCNTs in comparison to pristine MWCNTs. Three characteristic peaks concerned with MWCNTs were their D-band at $1333.33 \mathrm{~cm}^{-1}$, G-band at $1572 \mathrm{~cm}^{-1}$, and second-order harmonic $\mathrm{G}^{\prime}$-band at $2677.54 \mathrm{~cm}^{-1}[44,45]$. Clearly, from Figure 4, the tangential G-band derived from the graphite-like in-plane mode [46] was still retained after functionalization at $21 \mathrm{hrs}$ reflux time, revealing that the graphitic carbon structure with sp2 bonds 


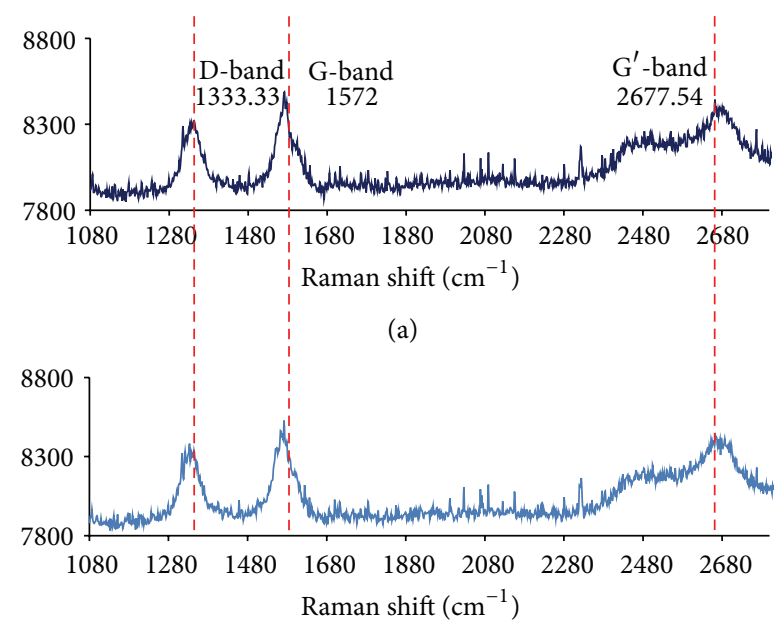

(b)

FIGURE 4: Raman spectra of (a) 21 hrs f-MWCNTs in comparison to (b) MWCNTs.

of f-MWCNTs was preserved. Besides, the presence of irregularities in the structure is showed by lower D-band and $G^{\prime}$ band compared to G-band observed in Figure 4 reflecting fMWCNTs samples with high purification and low impurities. Basically, the Raman spectra of MWCNT are usually showing a very intense D-band and a significant broadening effect [47] which is similar to the spectra of chars and carbon blacks. Referring to Figure 4, it was observed that covalent functionalization of $\mathrm{f}-\mathrm{MWCNT}$ does not generally result in obvious changes in D-band-to-G-band intensity ratios $\left(I_{\mathrm{D}} / I_{\mathrm{G}}\right)$. Similar observation was also reported elsewhere [4850]. This reveals that functionalization process is resulting much in opening the end cap of multiwall nanotubes only rather than destructing the whole multiwall structure.

Figure 5 shows the Raman spectra of UF-MWCNTs in comparison to conventional UF. Here the Raman spectra are collected over the $900-1700 \mathrm{~cm}^{-1}$ spectral range, corresponding to fundamental modes associated with C-N molecular bonds [51, 52]. The most pronounced Raman feature in the spectrum subjected to UF is a strong sharp and narrow peak around $\sim 1000 \mathrm{~cm}^{-1}$ for both UF-MWCNTs and UF samples. This is the characterization Raman peak for highly crystalline structure of urea [53]. Urea bands centered at around 1000 and $\sim 1170 \mathrm{~cm}^{-1}$ correspond to N-C-N stretching and $\mathrm{NH}_{2}$ rocking, respectively $[54,55]$. These two important bands correlated with UF were maintained after grafting with $21 \mathrm{hrs}$ f-MWCNTs revealing the success of grafting process in producing high performance UF-MWCNTs fertilizer.

Significantly, the characteristic absorption peak for $21 \mathrm{hrs}$ f-MWCNTs which is D-band at $1333.33 \mathrm{~cm}^{-1}$ was strongly attenuated with new peak observed at $1459 \mathrm{~cm}^{-1}$ for UFMWCNTs after urea was grafted to f-MWCNTs. Furthermore, the G-band at $1572 \mathrm{~cm}^{-1}$ for f-MWCNTs was split into two peaks at 1542.5 and $1571.1 \mathrm{~cm}^{-1}$ for UF-MWCNTs sample. This observation might be strongly correlated to grafting process of $\mathrm{N}$ from UF to f-MWCNTs that takes place at opened end tubes and significantly changes their graphitic structure.
TABLE 3: Results of CCD.

\begin{tabular}{lccc}
\hline Run & $\begin{array}{c}\text { Response 1 } \\
\text { NUE }\end{array}$ & $\begin{array}{c}\text { Response } 2 \\
\text { NU }\end{array}$ & $\begin{array}{c}\text { Response 3 } \\
\text { TDW }\end{array}$ \\
\hline 1 & 86.29 & 1182.12 & 236.95 \\
2 & 86.16 & 1100.00 & 185.00 \\
3 & 85.20 & 1344.75 & 181.41 \\
4 & 85.00 & 1100.00 & 175.00 \\
5 & 86.25 & 1181.60 & 182.22 \\
6 & 83.85 & 1256.30 & 153.63 \\
7 & 96.35 & 1363.55 & 170.52 \\
8 & 71.38 & 977.84 & 152.11 \\
9 & 86.50 & 1185.02 & 198.17 \\
10 & 81.09 & 1134.47 & 200.95 \\
11 & 86.67 & 1187.41 & 174.09 \\
12 & 75.46 & 1087.31 & 161.93 \\
13 & 90.00 & 1189.00 & 173.88 \\
\hline
\end{tabular}

3.5. Statistical Analysis of Responses Studied. The optimum conditions for fertilizer NU, NUE, and TDW of rice growth were determined by means of the Central Composite Design (CCD) of RSM. The overall results are shown in Table 3. For UF-MWCNTs fertilizer, the obtained responses were varied between 71 and 96\%, 978 and $1363 \mathrm{mg} / \mathrm{pot}$, and 152 and $237 \mathrm{~g} /$ pot for NUE, NU, and TDW, respectively. Several researchers have conducted studies on NUE attainments for rice plant under $\mathrm{N}$ fertilizer treatments [56-58]. Recently, Hashim et al. [56] reported that the NUE of MR219, Malaysian local rice variety, under standard UF treatment reached up to $50 \%$. The remaining $50 \%$ of $\mathrm{N}$ from the applied fertilizer either remained in the soil or was lost to the environment. Similarly, low NUE by rice also were reported elsewhere $[59,60]$. Accordingly, the NUE of UF for rice treatment is still relatively low and led to uncontrolled utilization in larger amount as to ensure efficient rice growth and high rice yield. Thus, apparently, application of UF-MWCNTs to rice plants enhances the NUE response significantly. Subsequently, the results of NUE, NU, and TDW as responses for rice treated with UF-MWCNTs structured by RSM with CCD were presented in Table 3, and their corresponding equations are listed in Table 4.

The analysis of variance for response surface quadratic model of NUE to test its adequacy was shown in Table 5. The modelling equation, in terms of both coded and actual factors to represent the $\operatorname{NUE}\left(Y_{1}\right)$, was listed in Table 4 that was evaluated by the regression coefficients, $F$-values, $p$ values, correlation coefficient $(R)$, and the determination coefficient $\left(R^{2}\right)$. The proposed model suggests that the amount of $\mathrm{f}-$ MWCNTs $\left(X_{1}\right)$ and the functionalization reflux time $\left(X_{2}\right)$ had a significant effect on NUE response. The coefficient of determination value $\left(R^{2}=0.8805\right)$ indicates that the response model can explain about $88 \%$ of the total variations. Additionally, the coefficient of adjusted determination value (Adj $R^{2}=0.7952$ ) was also high enough to indicate the significance of the selected model. The model $F$-value of 10.32 implies that the model is significant. It means that 
TABLE 4: Final equations to predict the responses as a function of specified design factors $\left({ }^{\mathrm{a}} X_{1}\right.$ and $\left.{ }^{\mathrm{b}} X_{2}\right)$ in terms of coded and actual factors for parameters.

\begin{tabular}{lcc}
\hline Responses & Coded factors & Actual factors \\
\hline Nitrogen use efficiency (NUE) $\left(Y_{1}\right)$ & $Y_{1}=86.4+4.83 X_{1}+4.44 X_{2}$ & $Y_{1}=7.23759-8.92803 X_{1}$ \\
& $+2.79 X_{1} X_{2}-3.39 X_{1}^{2}-1.74 X_{2}^{2}$ & $+7.06214 X_{2}+4.65833 X_{1} X_{2}$ \\
& & $-84.64447 X_{1}^{2}-0.19386 X_{2}^{2}$ \\
Nitrogen uptake $\left(Y_{2}\right)$ & $Y_{2}=1181.23+81.47 X_{1}+50.81 X_{2}$ & $Y_{2}=1918.97352+394.43873 X_{1}$ \\
& $+29.90 X_{1} X_{2}-58.94 X_{1}^{2}+28.56 X_{2}^{2}$ & $-112.27217 X_{2}+49.83750 X_{1} X_{2}$ \\
& & $-1473.60719 X_{1}^{2}+3.17386 X_{2}^{2}$ \\
Total Dry Weight (TDW) $\left(Y_{3}\right)$ & $Y_{3}=175.20+1.68 X_{1}$ & $Y_{3}=77.85286+81.47131 X_{1}$ \\
& $+9.42 X_{2}-10.06 X_{1} X_{2}$ & $+23.48060 X_{2}-16.77083 X_{1} X_{2}$ \\
& $+15.25 X_{1}^{2}-3.83 X_{2}^{2}$ & $+381.37462 X_{1}^{2}-0.42530 X_{2}^{2}$ \\
\hline
\end{tabular}

${ }^{\mathrm{a}} X_{1}$ is amount of f-MWCNTs.

${ }^{\mathrm{b}} X_{2}$ is functionalization reflux time.

TABLE 5: Analysis of variance for NUE using CCD.

\begin{tabular}{|c|c|c|c|c|c|}
\hline Source & Sum of squares & Degree of freedom & Mean square & $F$-value & $p$ value \\
\hline Model & 462.90 & 5 & 92.58 & 10.32 & 0.0040 \\
\hline${ }^{\mathrm{a}} X_{1}$ & 119.67 & 1 & 119.67 & 13.34 & 0.0082 \\
\hline${ }^{\mathrm{b}} X_{2}$ & 236.74 & 1 & 236.74 & 26.39 & 0.0013 \\
\hline$X_{1} X_{2}$ & 31.25 & 1 & 31.25 & 3.48 & 0.1042 \\
\hline$X_{1}^{2}$ & 52.66 & 1 & 52.66 & 5.87 & 0.0459 \\
\hline$X_{2}^{2}$ & 73.80 & 1 & 73.80 & 8.23 & 0.0241 \\
\hline Residual & 62.80 & 7 & 8.97 & & \\
\hline Lack-of-Fit & 62.80 & 3 & 20.93 & & \\
\hline Pure error & 0.000 & 4 & 0.000 & & \\
\hline Cor total & 525.70 & 12 & & & \\
\hline
\end{tabular}

$R$-Squared $=0.8805 ;$ Adj $R$-Squared $=0.7952 ;$ Pred $R$-Squared $=-1.1297 ;$ Adeq Precision $=11.202$.

${ }^{\mathrm{a}} X_{1}$ is amount of f-MWCNTs.

${ }^{\mathrm{b}} X_{2}$ is functionalization reflux time.

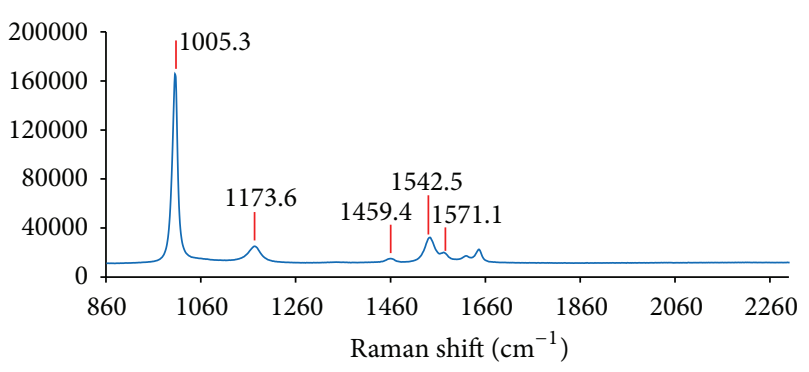

(a)

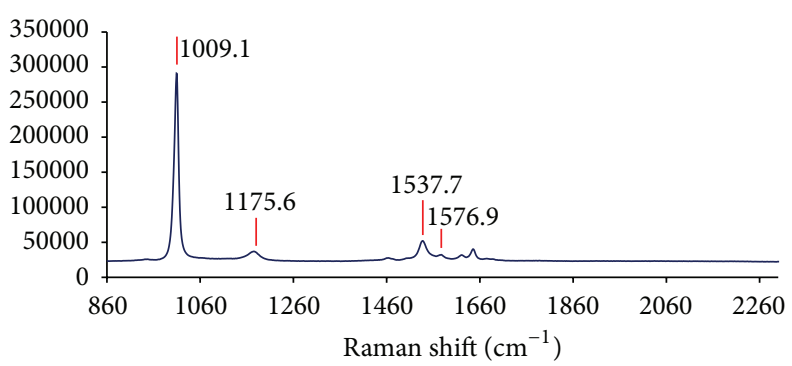

(b)

FIGURE 5: Raman spectra of (a) UF-MWCNTs in comparison to (b) UF.

there is only about $0.40 \%$ chance that $F$-value this large could occur due to noise. $p$ values less than 0.0500 indicate that the model terms are also significant. In this case the individual effects of $X_{1}, X_{2}, X_{1}^{2}$, and $X_{2}^{2}$ are significant model terms. However, insignificant $p$ value was found for the interaction $\left(X_{1} X_{2}\right)$ between the design factors. Even an insignificant $p$ value does not automatically specify that the particular research project has "failed to disprove the null hypothesis" [61], but here, in this case, conclusions should only be made after consideration of other significant factors and primary objectives of the study. Hence, the amount of f-MWCNTs $\left(X_{1}\right)$ and the functionalization reflux time $\left(X_{2}\right)$ had a significant positive effect individually on NUE response by paddy. NUE response increased with increasing amount of 
TABLE 6: Analysis of variance for $\mathrm{N}$ uptake using CCD.

\begin{tabular}{|c|c|c|c|c|c|}
\hline Source & Sum of squares & Degree of freedom & Mean square & $F$-value & $p$ value \\
\hline Model & 93968.46 & 5 & 18793.69 & 5.18 & 0.0263 \\
\hline${ }^{\mathrm{a}} X_{1}$ & 34088.30 & 1 & 34088.30 & 9.39 & 0.0182 \\
\hline${ }^{\mathrm{b}} X_{2}$ & 30984.95 & 1 & 30984.95 & 8.54 & 0.0223 \\
\hline$X_{1} X_{2}$ & 3576.64 & 1 & 3576.64 & 0.99 & 0.3539 \\
\hline$X_{1}^{2}$ & 15960.55 & 1 & 15960.55 & 4.40 & 0.0742 \\
\hline$X_{2}^{2}$ & 19780.29 & 1 & 19780.29 & 5.45 & 0.0522 \\
\hline Residual & 25401.24 & 7 & 3628.75 & & \\
\hline Lack-of-Fit & 24231.77 & 3 & 8077.26 & 27.63 & 0.0039 \\
\hline Pure error & 1169.47 & 4 & 292.37 & & \\
\hline Cor total & $1.194 E+005$ & 12 & & & \\
\hline
\end{tabular}

$R$-Squared $=0.7872$; Adj $R$-Squared $=0.6352$; Pred $R$-Squared $=-2.1426$; Adeq Precision $=8.519$.

${ }^{\mathrm{a}} X_{1}$ is amount of $\mathrm{f}-\mathrm{MWCNT}$.

${ }^{\mathrm{b}} \mathrm{X}_{2}$ is functionalization reflux time.

TABLE 7: Analysis of variance for Total Dry Weight (TDW) using CCD.

\begin{tabular}{|c|c|c|c|c|c|}
\hline Source & Sum of squares & Degree of freedom & Mean square & $F$-value & $p$ value \\
\hline Model & 3606.26 & 5 & 721.25 & 2.10 & 0.1799 \\
\hline${ }^{\mathrm{a}} X_{1}$ & 14.57 & 1 & 14.57 & 0.042 & 0.8426 \\
\hline${ }^{\mathrm{b}} X_{2}$ & 1063.90 & 1 & 1063.90 & 3.10 & 0.1216 \\
\hline$X_{1} X_{2}$ & 405.02 & 1 & 405.02 & 1.18 & 0.3132 \\
\hline$X_{1}^{2}$ & 1069.03 & 1 & 1069.03 & 3.12 & 0.1208 \\
\hline$X_{2}^{2}$ & 355.18 & 1 & 355.18 & 1.04 & 0.3427 \\
\hline Residual & 2400.72 & 7 & 342.96 & & \\
\hline Lack-of-Fit & 2400.27 & 3 & 800.09 & 7054.21 & $<0.0001$ \\
\hline Pure error & 0.45 & 4 & 0.11 & & \\
\hline Cor total & 6006.98 & 12 & & & \\
\hline
\end{tabular}

$R$-Squared $=0.6003 ;$ Adj $R$-Squared $=0.3149 ;$ Pred $R$-Squared $=-2.3503 ;$ Adeq Precision $=5.643$.

${ }^{\mathrm{a}} X_{1}$ is amount of f-MWCNTs.

${ }^{\mathrm{b}} \mathrm{X}_{2}$ is functionalization reflux time.

f-MWCNTs $\left(X_{1}\right)$ and the functionalization reflux time, while the interaction between $X_{1}$ and $X_{2}$ had a negative effect on NUE response.

A negative "Pred R-Squared" implies that the overall mean is a better predictor of NUE than the current model. "Adeq Precision" which measures the signal-to-noise ratio was at about 11.202 indicating an adequate signal. A ratio greater than 4 is desirable. Hence, this model can be used to navigate the design space.

Furthermore, the ANOVA for response surface quadratic model of NU to test its adequacy was presented in Table 6. The modelling equations, in terms of both coded and actual factors to represent the NU $\left(Y_{2}\right)$, were listed in Table 4. Similar to NUE, the proposed model suggests that the amount of $\mathrm{f}$ MWCNTs $\left(X_{1}\right)$ and functionalization reflux time $\left(X_{2}\right)$ had a significant effect on NU by paddy treated with UF-MWCNTs. Here, the coefficient of determination value $\left(R^{2}=0.7872\right)$ indicates that the response model can explain about $79 \%$ of the total variations which is lower than NUE response. Additionally, the coefficient of adjusted determination value (Adj $R^{2}=0.6352$ ) was also high enough to indicate the significance of the model. The model $F$-value of 5.18 implies that the model is significant. There is only a $2.63 \%$ chance that $F$-value this large could occur due to noise. $p$ value of 0.0263 , which is less than 0.0500 , implies that the model term is significant. In comparison with NUE, in this case $X_{1}$ and $X_{2}$ only are significant model terms. Individually, the increase in amount of $\mathrm{f}-\mathrm{MWCNT}$ and the functionalization reflux time positively increase the NU response by paddy, while the interaction between the "Lack-of-Fit $F$-value" of 27.63 implies that there is only $0.39 \%$ chance that a "Lack-of-Fit $F$-value" this large could occur due to noise. Again, a negative "Pred $R$ Squared" suggests that the overall mean is a better predictor of NU than the current suggested model. Furthermore, "Adeq Precision" of 8.519 indicates an adequate signal. Thus this model also can be used to navigate the design space.

Next, the ANOVA for response surface quadratic model of TDW to test its adequacy was shown in Table 7. The modelling equations in terms of both coded and actual factors to represent the TDW $\left(Y_{3}\right)$ were listed in Table 3. Contradicting with NUE and NU responses, the proposed model suggested that the amount of $\mathrm{f}$-MWCNTs $\left(X_{1}\right)$ and functionalization reflux time $\left(X_{2}\right)$ had not provided a significant effect on TDW of paddy treated with UF-MWCNTs. Here, the model shows 


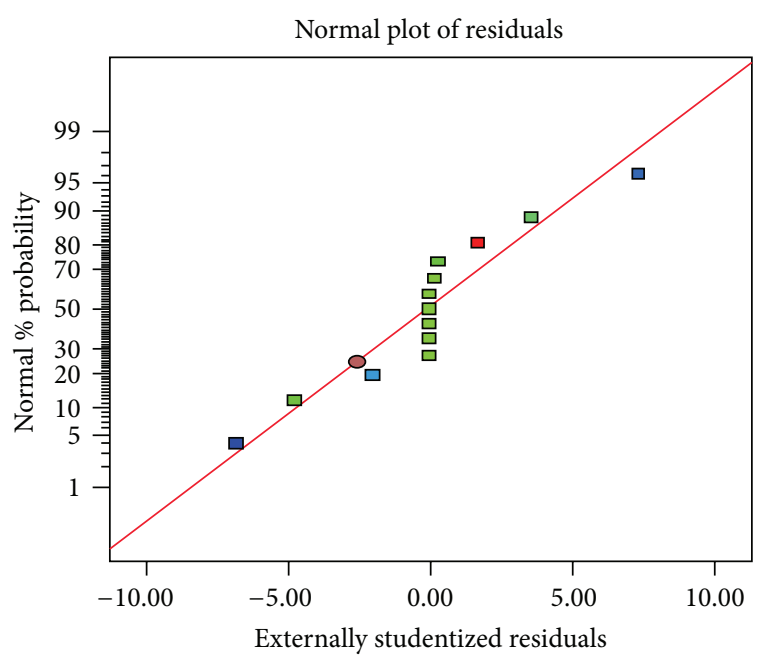

(a)

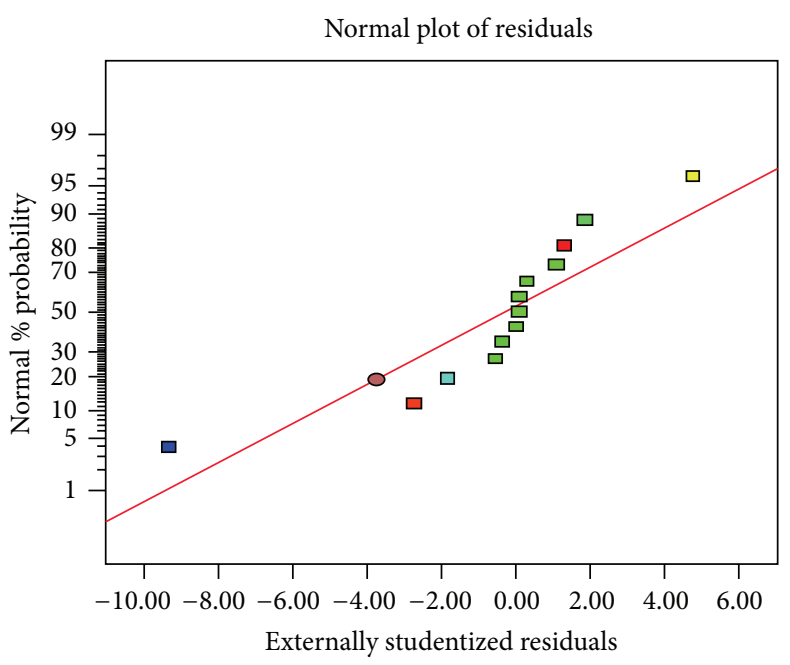

(b)

FIGURE 6: Design Expert plot. Normal probability plot of the standardized residual for NUE (a) and NU (b).

that the coefficient of determination value $\left(R^{2}=0.6003\right)$ indicates that the TDW response model only can explain about $60 \%$ of the total variations which is much lower than NUE and NU responses. Moreover, the coefficient of adjusted determination value (Adj $R^{2}=0.3149$ ) was also too low to indicate the significance of the model. It means that about $68.51 \%$ of total variation of the TDW response was not explained by the model. The model $F$-value of 2.10 implies that the model is not significantly relative to the noise factor. This result implies that there is a $17.99 \%$ chance that $F$-value this large could occur due to noise. $p$ values of less than 0.0500 indicate that model terms are significant. However, in this case no significant model terms were detected. The "Lack-of-Fit $F$-value" of 7054.21 implies that there is only about $0.01 \%$ chance that a "Lack-of-Fit $F$-value" this large could occur due to noise. Thus TDW of paddy treated with UF-MWCNTs are considered insignificant model terms, which have limited influence on this optimization models for the development of UF-MWCNTs fertilizer.

In order to further ensure that the selected model provides an adequate approximation of the real system, the normal probability plots of the studentized residuals and diagnostics are provided by the Design Expert 9 software. The normal probability plots illustrated in Figure 6 demonstrate that the normal probability plots of the studentized residuals for two quadratic models which are significant model terms including NUE (Figure 6(a)) and NU (Figure 6(b)) by paddy treated with UF-MWCNTs. A normal probability plot indicates that if the residuals follow a normal distribution, the points will be scattered following a straight line for each of the responses [62]. Consequently, the data for both NUE and NU responses can be possibly reflected as normally distributed in the models.

3.6. Treatment Efficiency Evaluation. The 3D response surface plots are useful in assessing both individual and interaction relationships between independent variables and the responses [63]. These plots were obtained by computations using the Design Expert 9 software and were depicted in Figure 7. As shown by contour plots in Figures 7(a)7(d), the maximum observed NUE and NU responses of UF-MWCNTs by rice were $96.35 \%$ and $1363.55 \mathrm{mg} / \mathrm{pot}$, respectively, at $0.50 \mathrm{wt} \%$ amount of f-MWCNTs and $21 \mathrm{hrs}$ of functionalization reflux time. The increment of UFMWCNTs for NUE and NU is accredited to the increase in f-MWCNTs amount and functionalization reflux time until $0.5 \mathrm{wt} \%$ MWCNTs and 21-hour functionalization reflux time accordingly and results in decrease in value of NUE and NU responses of UF-MWCNTs at further increment. Hence, the increases of both f-MWCNTs amount and functionalization reflux time until optimum values are two main factors affecting the UF-MWCNTs NUE and NU responses by paddy. According to the optimization process using Design Expert 9, the desired goals for each responses (NUE and NU) were chosen to be maximized to achieve the highest performance of UF-MWCNTs fertilizer.

Finally, the confirmation report from the design software based on the $95 \%$ confidence level presents the optimum design factors (MWCNTs \% and functionalization reflux time) (Table 8) and respective desired responses (NUE \% and $\mathrm{N}$ uptake) (Table 9) for the development of UF-MWCNTs fertilizer. As shown in Table 8, the optimum value of $\mathrm{f}$ MWCNTs and functionalization reflux time for maximum performance of UF-MWCNTs fertilizer were confirmed to be $0.50 \mathrm{wt} \%$ and $21 \mathrm{hrs}$, respectively. Additionally, referring to Table 8, 93.34 NUE \%, $1313.04 \mathrm{mg} /$ pot NU, and $187.67 \mathrm{~g} / \mathrm{pot}$ TDW of paddy are predicted based on the model under optimized operational condition of design factors. The desirability function value was observed to be 0.684 for these optimum design factors.

\section{Conclusion}

In conclusion, the functionalization of MWCNTs by strong acid treatment resulted in the formation of opened ends tubes still retaining their hollow sidewalls structure, as observed 
TABLE 8: Optimization results for design factors of UF-MWCNTs fertilizer.

\begin{tabular}{lcccc}
\hline Factors & Name & Level & Low level & High level \\
\hline${ }^{\mathrm{a}} X_{1}$ & f-MWCNTs & 0.50 & 0.10 & 0.50 \\
${ }^{\mathrm{b}} X_{2}$ & Functionalization reflux time & 21.00 & 15.00 & 21.00 \\
\hline
\end{tabular}

Confidence level = 95\%.

${ }^{\mathrm{a}} X_{1}$ is amount of f-MWCNTs.

${ }^{\mathrm{b}} \mathrm{X}_{2}$ is functionalization reflux time.

TABLE 9: Optimization results for maximum responses of UF-MWCNTs fertilizer.

\begin{tabular}{|c|c|c|c|c|c|c|}
\hline Responses & Pred mean & Std. dev. & SE Pred & 95\% PI low & 95\% PI high & Desirability \\
\hline NUE & 93.34 & 2.99529 & 3.73 & 84.52 & 102.15 & \multirow{3}{*}{0.684} \\
\hline $\mathrm{NU}$ & 1313.04 & 60.2391 & 74.94 & 1135.83 & 1490.25 & \\
\hline TDW & 187.67 & 18.5192 & 23.04 & 133.19 & 242.15 & \\
\hline
\end{tabular}

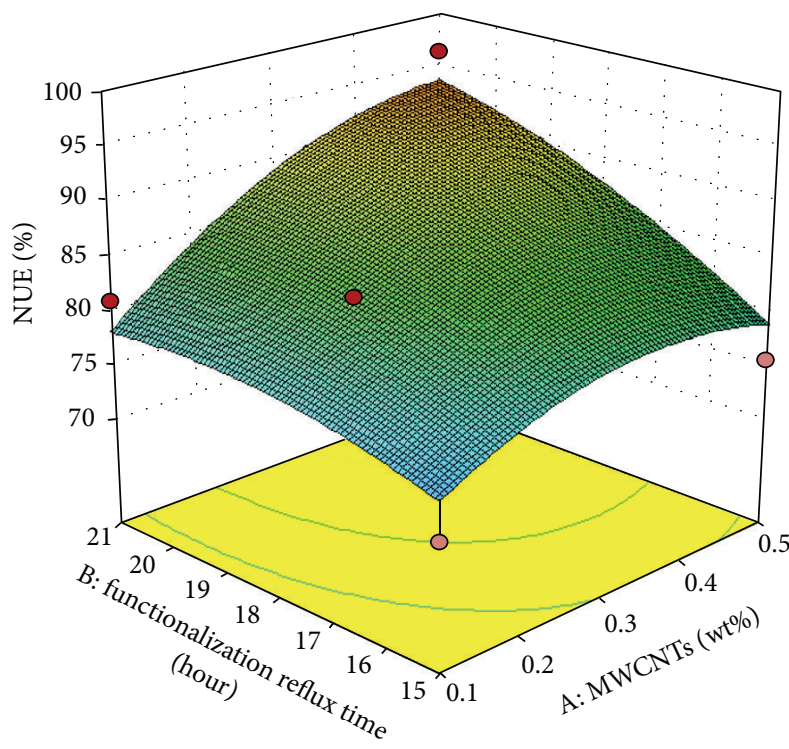

(a)

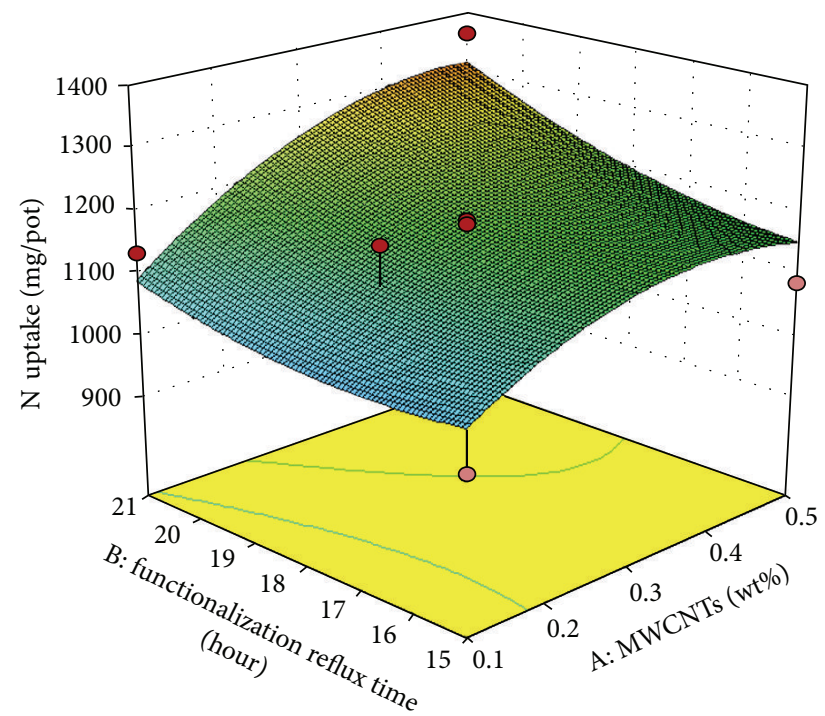

(c)

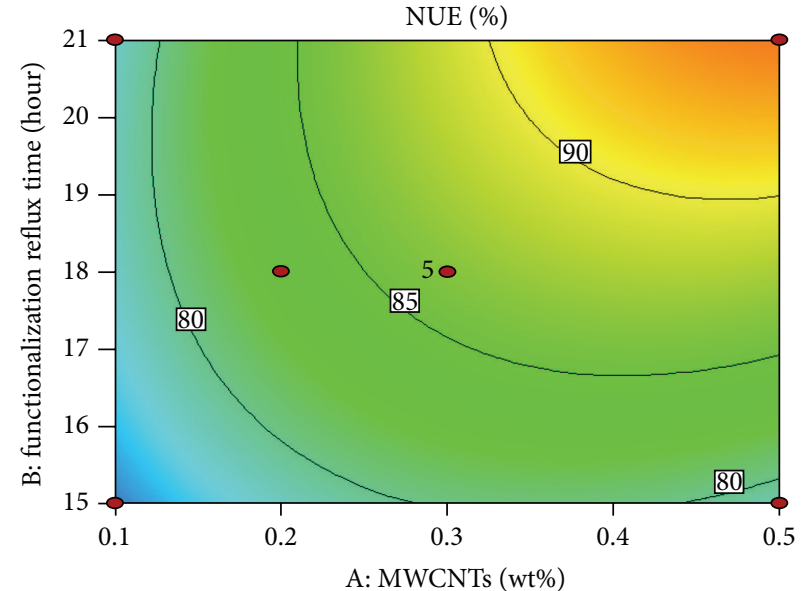

(b)

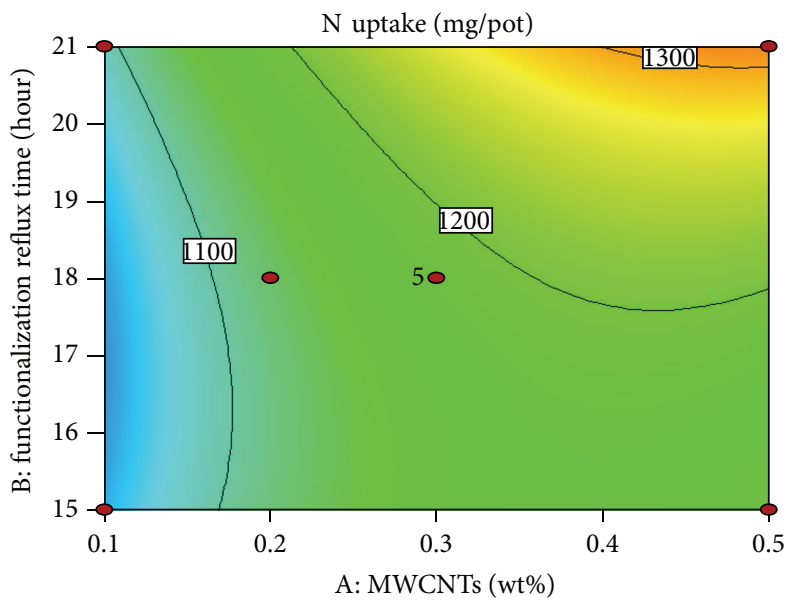

(d)

FIGURE 7: 3D response surface plot of NUE (a) and NU (c) coupled with contour plots of NUE (b) and NU (d) of paddy as a function of f-MWCNTs (\%) and functionalization reflux time (hour). 
via morphological evaluation using FESEM followed by TEM and further confirmed through FT-IR and Raman spectroscopy analysis. These conditions also strongly facilitate the separation of nanotube bundles into individual tubes encouraging excellent biocompatibility between f-MWCNTs and UF. Furthermore, using RSM with CCD approach, the ANOVA of two quadratic models demonstrates that responses including NUE and NU by rice treated with UF-MWCNTs are significant model terms with $p$ value of less than 0.05. Insignificant model term like TDW was excluded from the study to improve the models of optimization process for development of UF-MWCNTs fertilizer for enhancement of the plant growth. Apparently, RSM with CCD provides valuable information regarding the interaction between design factors which were f-MWCNTs wt $\%$ and functionalization reflux time which helps for recognition of possible optimum values of the chosen design factors. The optimum design factors obtained at $0.50 \mathrm{wt} \%$ amount of f-MWCNTs which have reflux in nitric acid for $21 \mathrm{hrs}$ for functionalization process needed for the development of UF-MWCNTs show great performances up to $96 \%$ NUE and $1180 \mathrm{mg} /$ pot for NU. This new urea-MWCNTs (UFMWCNTs) approach delivers a promising improvement in NU and NUE for efficient plant nutrition of rice.

\section{Competing Interests}

The authors declare that they have no competing interests.

\section{Acknowledgments}

Authors acknowledged the Long Term Research Grant Scheme (LRGS) by Ministry of Education, Malaysia, awarded to Universiti Teknikal Malaysia Melaka (UTeM) Project 3 under the OneBaja Project (Universiti Teknologi Petronas), for supporting and funding this work.

\section{References}

[1] X. Fan, D. Xie, J. Chen et al., "Over-expression of OsPTR6 in rice increased plant growth at different nitrogen supplies but decreased nitrogen use efficiency at high ammonium supply," Plant Science, vol. 227, pp. 1-11, 2014.

[2] P. J. Lea and J.-F. Morot-Gaudry, Eds., Plant Nitrogen, Springer, 2001.

[3] E. Epstein, Mineral Nutrition of Plants: Principles and Perspectives, 1972.

[4] M. E. Trenkel, Slow and Controlled Released and Stabilized Fertilizer an Option for Enhancing Nitrogen Use Efficiency in Agriculture, vol. 53, 2nd edition, 2010.

[5] L. M. Maene, in Proceedings of the 45th Annual Meeting Fertilizer Industry Roundtable, 1995.

[6] Z.-Z. Li, J.-F. Chen, F. Liu et al., "Study of UV-shielding properties of novel porous hollow silica nanoparticle carriers for avermectin," Pest Management Science, vol. 63, no. 3, pp. 241246, 2007.

[7] P. S. Vijayakumar, O. U. Abhilash, B. M. Khan, and B. L. V. Prasad, "Nanogold-loaded sharp-edged carbon bullets as plantgene carriers," Advanced Functional Materials, vol. 20, no. 15, pp. 2416-2423, 2010.
[8] V. Ghormade, M. V. Deshpande, and K. M. Paknikar, "Perspectives for nano-biotechnology enabled protection and nutrition of plants," Biotechnology Advances, vol. 29, no. 6, pp. 792-803, 2011.

[9] M. A. Wilson, N. H. Tran, A. S. Milev, G. S. K. Kannangara, H. Volk, and G. Q. M. Lu, "Nanomaterials in soils," Geoderma, vol. 146, no. 1-2, pp. 291-302, 2008.

[10] R. Nair, S. H. Varghese, B. G. Nair, T. Maekawa, Y. Yoshida, and D. S. Kumar, "Nanoparticulate material delivery to plants," Plant Science, vol. 179, no. 3, pp. 154-163, 2010.

[11] A. Pérez-de-Luque and D. Rubiales, "Nanotechnology for parasitic plant control," Pest Management Science, vol. 65, no. 5, pp. 540-545, 2009.

[12] M. García, T. Forbe, and E. Gonzalez, "Potential applications of nanotechnology in the agro-food sector," Ciencia e Tecnologia de Alimentos, vol. 30, no. 3, pp. 573-581, 2010.

[13] R. Sharon, M. Choudhary, and A. Kumar, "Nanotechnology in agricultural diseasesd and food safety," Journal of Phytology, vol. 2, pp. 83-92, 2010.

[14] A. Bhattacharyya, A. Bhaumik, P. U. Rani, S. Mandal, and T. T. Epidi, "Nano-particles-a recent approach to insect pest control," African Journal of Biotechnology, vol. 9, no. 24, pp. 3489-3493, 2010.

[15] B. Srilatha, "Nanotechnology in agriculture," Journal of Nanomedicine \& Nanotechnology, vol. 2, no. 7, article 123, 2011.

[16] L. Rashidi and K. Khosravi-Darani, "The applications of nanotechnology in food industry," Critical Reviews in Food Science and Nutrition, vol. 51, no. 8, pp. 723-730, 2011.

[17] L. Zheng, F. Hong, S. Lu, and C. Liu, "Effect of nano-TiO on strength of naturally aged seeds and growth of spinach," Biological Trace Element Research, vol. 104, no. 1, pp. 83-91, 2005.

[18] L. R. Khot, S. Sankaran, J. M. Maja, R. Ehsani, and E. W. Schuster, "Applications of nanomaterials in agricultural production and crop protection: a review," Crop Protection, vol. 35, pp. 6470, 2012.

[19] J. V. Anguita, D. C. Cox, M. Ahmad, Y. Y. Tan, J. Allam, and S. R. P. Silva, "Highly transmissive carbon nanotube forests grown at low substrate temperature," Advanced Functional Materials, vol. 23, no. 44, pp. 5502-5509, 2013.

[20] Q. Liu, B. Chen, Q. Wang et al., "Carbon nanotubes as molecular transporters for walled plant cells," Nano Letters, vol. 9, no. 3, pp. 1007-1010, 2009.

[21] C. M. Lu, C. Y. Zhang, and J. Q. Wen, "Research of the effect of nanometer materials on germination and growth enhancement of glycine max and its mechanism," Soybean Science, vol. 21, no. 3, pp. 168-172, 2002.

[22] A.-X. Liu, Q.-M. Lu, Y.-J. Cao, Z.-W. Liao, and Q.-H. Xu, "Effects of composite nanomaterials on rice growth," Journal of Plant Nutrition and Fertilizer, vol. 13, no. 2, pp. 344-347, 2007.

[23] Z. J. F. Xiao Qiang, Z. S. Qing, Z. D. Fu, and W. Y. Jun, "Effects of slow/controlled release fertilizers felted and coated by nanomaterials on crop yield and quality," Plant Nutrition and Fertilizer Science, vol. 5, pp. 951-955, 2008.

[24] Z. M. Liu, J. Zhang, and Y. D. Zhang, "Study on application of nanometer biotechnology on the yield and quality of winter wheat," Journal of Anhui Agricultural Sciences, vol. 35, pp. 1557815580, 2008.

[25] Q. Yin-fei, S. Cai-hong, Q. Cai-fei et al., "Primarily study of the effects of nanometer carbon fertilizer synergist on the late rice," Acta Agriculturae Boreali-Sinica, supplement 2, pp. 249253, 2010. 
[26] J. A. Razak, S. H. Ahmad, C. T. Ratnam, M. A. Mahamood, J. Yaakub, and N. Mohamad, "Effects of EPDM-g-MAH compatibilizer and internal mixer processing parameters on the properties of NR/EPDM blends: an analysis using response surface methodology," Journal of Applied Polymer Science, vol. 132, no. 27, Article ID 42199, 2015.

[27] R. Chakravarti and V. Sahai, "Optimization of compactin production in chemically defined production medium by Penicillium citrinum using statistical methods," Process Biochemistry, vol. 38, no. 4, pp. 481-486, 2002.

[28] N. Mohamad, A. Muchtar, M. J. Ghazali, D. H. J. Mohd, and C. H. Azhari, "Epoxidized natural rubber-alumina nanoparticle composites: optimization of mixer parameters via response surface methodology," Journal of Applied Polymer Science, vol. 115, no. 1, pp. 183-189, 2010.

[29] D. Talei, A. Valdiani, M. Maziah, and M. Mohsenkhah, "Germination response of MR 219 rice variety to different exposure times and periods of $2450 \mathrm{MHz}$ microwave frequency," The Scientific World Journal, vol. 2013, Article ID 408026, 7 pages, 2013.

[30] N. M. Yatim, A. Shaaban, M. F. Dimin, and F. Yusof, "Statistical evaluation of the production of urea fertilizer-multiwalled carbon nanotubes using plackett burman experimental design," Procedia-Social and Behavioral Sciences, vol. 195, pp. 315-323, 2015.

[31] L. V. A. Reddy, Y.-J. Wee, J.-S. Yun, and H.-W. Ryu, "Optimization of alkaline protease production by batch culture of Bacillus sp. RKY3 through Plackett-Burman and response surface methodological approaches," Bioresource Technology, vol. 99, no. 7, pp. 2242-2249, 2008.

[32] J. Zhang and N.-F. Gao, "Application of response surface methodology in medium optimization for pyruvic acid production of Torulopsis glabrata TP19 in batch fermentation," Journal of Zhejiang University SCIENCE B, vol. 8, no. 2, pp. 98-104, 2007.

[33] A. I. Khuri and J. A. Cornell, Response Surfaces: Designs and Analyses, CRC Press, 2nd edition, 1996.

[34] J. Zhang, Z. Li, K. Li, W. Huang, and L. Sang, "Nitrogen use efficiency under different field treatments on maize fields in central China: a lysimeter and ${ }^{15} \mathrm{~N}$ study," Journal of Water Resource and Protection, vol. 4, no. 8, pp. 590-596, 2012.

[35] H. Hu, B. Zhao, M. E. Itkis, and R. C. Haddon, "Nitric acid purification of single-walled carbon nanotubes," The Journal of Physical Chemistry B, vol. 107, no. 50, pp. 13838-13842, 2003.

[36] V. Georgakilas, A. Demeslis, E. Ntararas et al., "Hydrophilic nanotube supported graphene-water dispersible carbon superstructure with excellent conductivity," Advanced Functional Materials, vol. 25, no. 10, pp. 1481-1487, 2015.

[37] P. Wick, P. Manser, L. K. Limbach et al., "The degree and kind of agglomeration affect carbon nanotube cytotoxicity," Toxicology Letters, vol. 168, no. 2, pp. 121-131, 2007.

[38] C. A. Poland, R. Duffin, I. Kinloch et al., "Carbon nanotubes introduced into the abdominal cavity of mice show asbestoslike pathogenicity in a pilot study," Nature Nanotechnology, vol. 3, no. 7, pp. 423-428, 2008.

[39] P. Patlolla, A. Knighten, and B. Tchounwou, "Multi-walled carbon nanotubes induce cytotoxicity, genotoxicity and apoptosis in normal human dermal fibroblast cells," Ethnicity \& Disease, vol. 20, pp. 1-17, 2010.

[40] X.-M. Tan, C. Lin, and B. Fugetsu, "Studies on toxicity of multiwalled carbon nanotubes on suspension rice cells," Carbon, vol. 47, no. 15, pp. 3479-3487, 2009.
[41] B. Wei, L. Zhang, and G. Chen, "A multi-walled carbon nanotube/poly(urea-formaldehyde) composite prepared by in situ polycondensation for enhanced electrochemical sensing," New Journal of Chemistry, vol. 34, no. 3, pp. 453-457, 2010.

[42] I.-Y. Jeon, D. W. Chang, N. A. Kumar, and J.-B. Baek, "Functionalization of carbon nanotubes," in Carbon Nanotubes-Polymer Nanocomposites, InTech, Rijeka, Croatia, 2011.

[43] C. Gao, Y. Z. Jin, H. Kong et al., "Polyurea-functionalized multiwalled carbon nanotubes: synthesis, morphology, and Raman spectroscopy," Journal of Physical Chemistry B, vol. 109, no. 24, pp. 11925-11932, 2005.

[44] M. Zdrojek, W. Gebicki, C. Jastrzebski, T. Melin, and A. Huczko, "Studies of multiwall carbon nanotubes using Raman spectroscopy and atomic force microscopy," Solid State Phenomena, vol. 99-100, pp. 265-268, 2004.

[45] L. Bokobza and J. Zhang, "Raman spectroscopic characterization of multiwall carbon nanotubes and of composites," Express Polymer Letters, vol. 6, no. 7, pp. 601-608, 2012.

[46] G. S. Duesberg, I. Loa, M. Burghard, K. Syassen, and S. Roth, "Polarized Raman spectroscopy on isolated single-wall carbon nanotubes," Physical Review Letters, vol. 85, no. 25, pp. 5436$5439,2000$.

[47] Z. Syrgiannis, A. Bonasera, E. Tenori et al., "Chemical modification of carbon nanomaterials (SWCNTs, DWCNTs, MWCNTs and SWCNHs) with diphenyl dichalcogenides," Nanoscale, vol. 7, no. 14, pp. 6007-6013, 2015.

[48] S. Botti, S. Laurenzi, L. Mezi, A. Rufoloni, and M. G. Santonicola, "Surface-enhanced Raman spectroscopy characterisation of functionalised multi-walled carbon nanotubes," Physical Chemistry Chemical Physics, vol. 17, no. 33, pp. 21373-21380, 2015.

[49] W. Zhou, S. Sasaki, and A. Kawasaki, "Effective control of nanodefects in multiwalled carbon nanotubes by acid treatment," Carbon, vol. 78, pp. 121-129, 2014.

[50] S. L. H. Rebelo, A. Guedes, M. E. Szefczyk, A. M. Pereira, J. P. Araújo, and C. Freire, "Progress in the Raman spectra analysis of covalently functionalized multiwalled carbon nanotubes: unraveling disorder in graphitic materials," Physical Chemistry Chemical Physics, vol. 18, no. 18, pp. 12784-12796, 2016.

[51] D. Lin-Vien, N. B. Colthup, W. G. Fateley, and J. G. Grasselli, The Handbook of Infrared and Raman Characteristic Frequencies of Organic Molecules, Elsevier, 1991.

[52] Y. Sun, Comparison and Combination of Near-Infrared and Raman Spectra for PLS and NAS Quantitation of Glucose, Urea and Lactate, University of Iowa, Iowa City, Iowa, USA, 2013.

[53] M. Mowry, D. Palaniuk, C. C. Luhrs, and S. Osswald, "Insitu Raman spectroscopy and thermal analysis of the formation of nitrogen-doped graphene from urea and graphite oxide," RSC Advances, vol. 3, no. 44, pp. 21763-21775, 2013.

[54] X. Hoccart and G. Turrell, "Raman spectroscopic investigation of the dynamics of urea-water complexes," The Journal of Chemical Physics, vol. 99, no. 11, pp. 8498-8503, 1993.

[55] R. L. Frost, J. Kristof, L. Rintoul, and J. T. Kloprogge, "Raman spectroscopy of urea and urea-intercalated kaolinites at $77 \mathrm{~K}$," Spectrochimica Acta-Part A: Molecular and Biomolecular Spectroscopy, vol. 56, no. 9, pp. 1681-1691, 2000.

[56] M. M. Hashim, M. K. Yusop, R. Othman, and S. A. Wahid, "Characterization of nitrogen uptake pattern in malaysian rice MR219 at different growth stages using $15 \mathrm{~N}$ isotope," Rice Science, vol. 22, no. 5, pp. 250-254, 2015. 
[57] Z. Dong, L. Wu, J. Chai, Y. Zhu, Y. Chen, and Y. Zhu, "Effects of nitrogen application rates on rice grain yield, nitrogen-use efficiency, and water quality in paddy field," Communications in Soil Science and Plant Analysis, vol. 46, no. 12, pp. 1579-1594, 2015.

[58] G. Chen, S. Guo, H. J. Kronzucker, and W. Shi, "Nitrogen use efficiency (NUE) in rice links to $\mathrm{NH} 4^{+}$toxicity and futile $\mathrm{NH} 4^{+}$ cycling in roots," Plant and Soil, vol. 369, no. 1-2, pp. 351-363, 2013.

[59] B. Singh, K. F. Bronson, Y. Singh, T. S. Khera, and E. Pasuquin, "Nitrogen-15 balance as affected by rice straw management in a rice-wheat rotation in northwest India," Nutrient Cycling in Agroecosystems, vol. 59, no. 3, pp. 227-237, 2001.

[60] D. J. Hatch, Controlling Nitrogen Flows and Losses, Wageningen Academic Publishers, 2004.

[61] Jaykaran, D. Saxena, P. Yadav, and N. D. Kantharia, "Nonsignificant $\mathrm{P}$ values cannot prove null hypothesis: absence of evidence is not evidence of absence," Journal of Pharmacy and Bioallied Sciences, vol. 3, no. 3, pp. 465-466, 2011.

[62] S. S. Abu Amr, H. A. Aziz, and M. J. Bashir, "Application of response surface methodology (RSM) for optimization of semiaerobic landfill leachate treatment using ozone," Applied Water Science, vol. 4, no. 3, pp. 231-239, 2014.

[63] A. Fakhri, "Application of response surface methodology to optimize the process variables for fluoride ion removal using maghemite nanoparticles," Journal of Saudi Chemical Society, vol. 18, no. 4, pp. 340-347, 2014. 

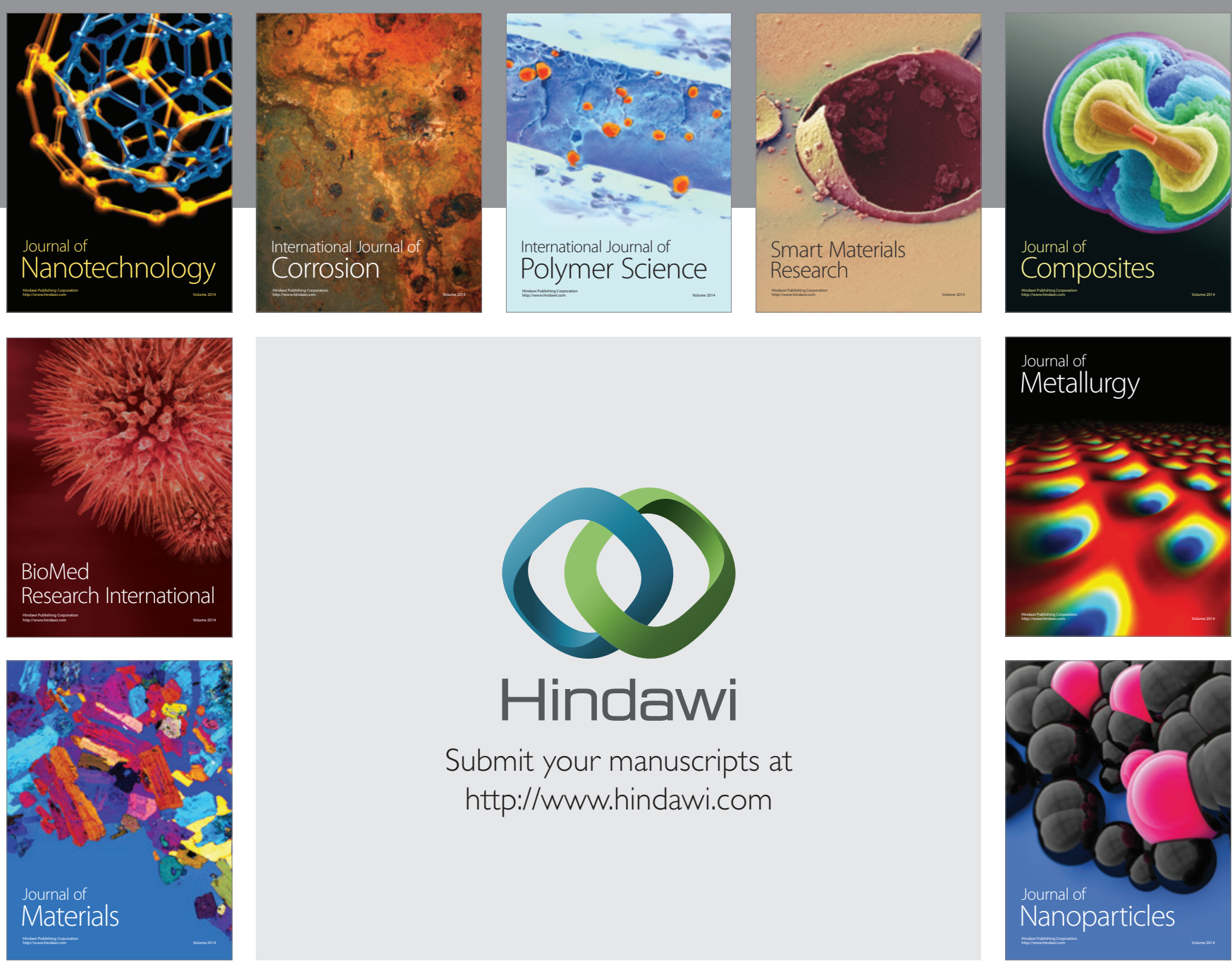

\section{Hindawi}

Submit your manuscripts at

http://www.hindawi.com

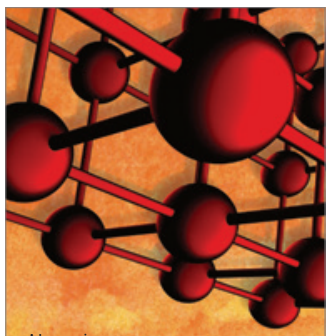

Materials Science and Engineering
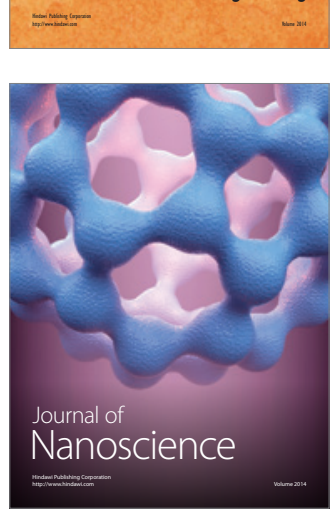
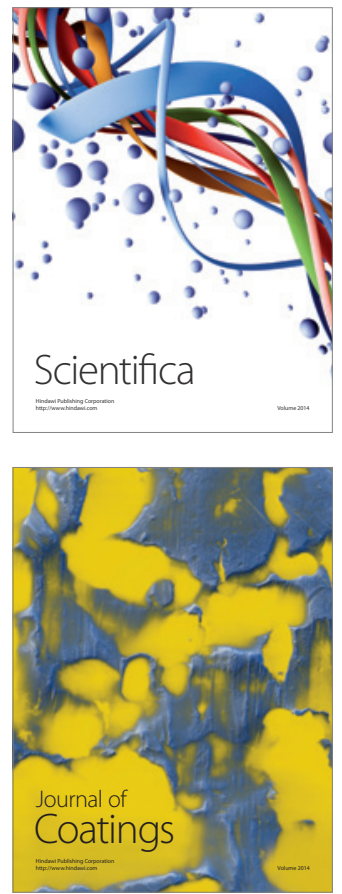
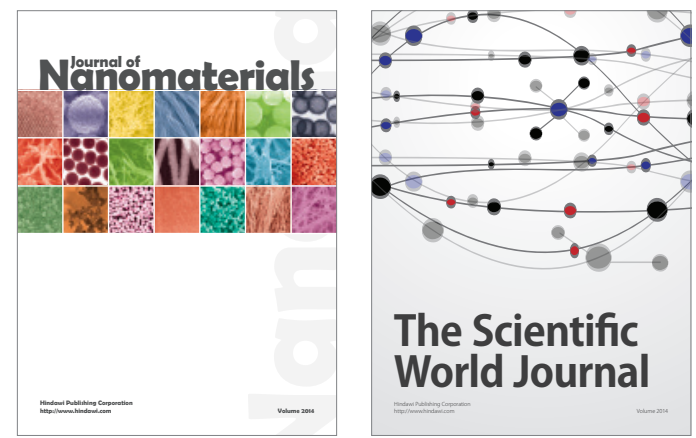

The Scientific World Journal
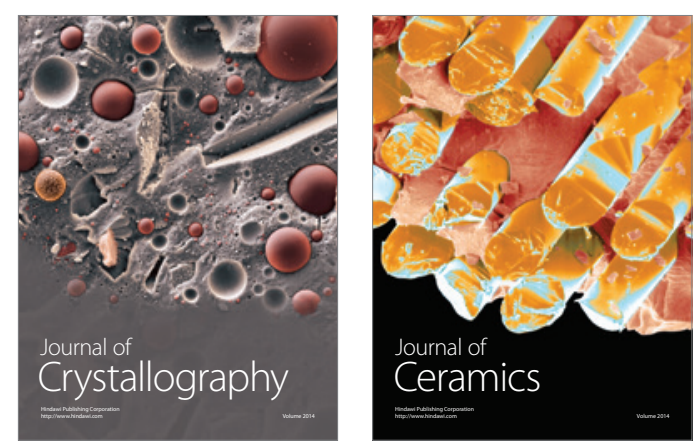
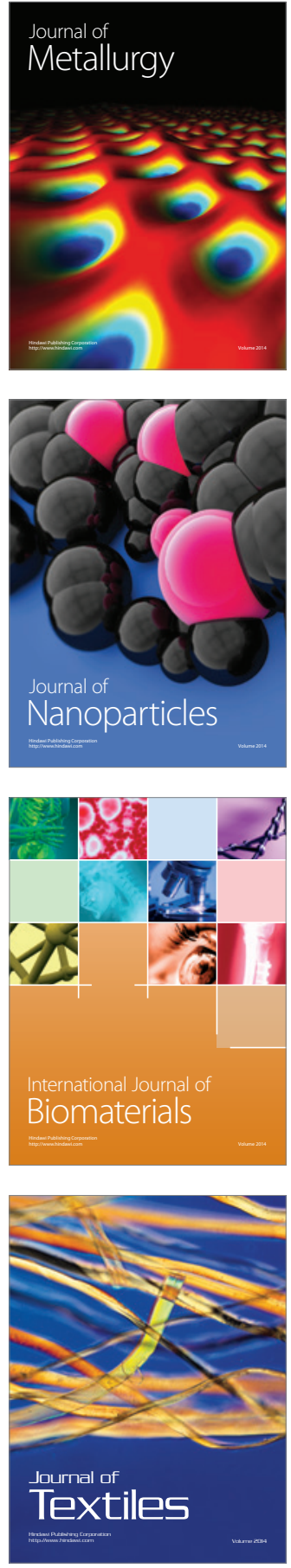